\title{
Reducing Conflict in the Wildland-Urban Interface ${ }^{1}$
}

Martha C. Monroe ${ }^{2}$

It is not easy to be in the middle of a conflict. Misunderstandings abound, feelings are hurt, and in some cases there might be no right answer to untangle the mess. Because conflicts seem to be part of every wildland-urban interface, it is important for extension agents and resource managers to consider skills for reducing or managing conflict. A variety of other EDIS documents provide background on the issues that may be at the heart of the conflict (e.g., forest management, prescribed fire, wildlife management, forest health, and growth management); this document provides suggestions for strategies to approach any conflict.

One solution to avoiding conflict is to build partnerships with the community, particularly with those who have different opinions. A National Forest supervisor in Alabama regularly meets with a community advisory council, which keeps open an avenue for residents to express concerns and get information (Figure 1). Recognizing the conflicts around identifying exotic plants as invasive, IFAS uses a coordinating council that represents a variety of perspectives to review documents and establish priorities. This type of networking and communication is even a good strategy after a conflict has occurred in order to help repair the damage and prevent future misunderstanding. The book Making Collaboration Work by Julia Wondolleck and Steve Yaffee is an excellent source of ideas and strategies from resource agencies across the United States.

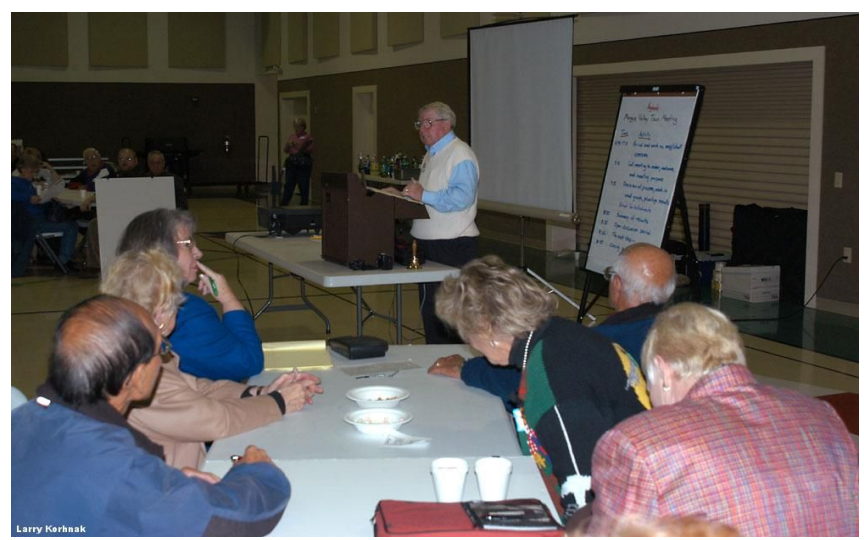

Figure 1. Community workshops can enable residents to understand issues and participate in designing solutions. Credits: Larry Korhnak

If you find yourself in the midst of a conflict, however, here are some tips for working toward a resolution.

Work to understand the underlying causes of different opinions. People may react to a statement or plan for many reasons: they do not like the plan, they were not involved in creating the plan, or the

1. This document is FOR198, one of a series of the School of Forest Resources and Conservation Department, Florida Cooperative Extension Service, Institute of Food and Agricultural Sciences, University of Florida. This fact sheet was first published in 2006 as part of Changing Roles: Wildland-Urban Interface Professional Development Program. It was reviewed and revised for EDIS in July 2008. Visit the EDIS Web Site at http://edis.ifas.ufl.edu.

2. Martha C. Monroe is a professor in the School of Forest Resources and Conservation, Institute of Food and Agricultural Sciences, University of Florida, Gainesville, Florida 32611.

The Institute of Food and Agricultural Sciences (IFAS) is an Equal Opportunity Institution authorized to provide research, educational information and other services only to individuals and institutions that function with non-discrimination with respect to race, creed, color, religion, age, disability, sex, sexual orientation, marital status, national origin, political opinions or affiliations. U.S. Department of Agriculture, Cooperative Extension Service, University of Florida, IFAS, Florida A. \& M. University Cooperative Extension Program, and Boards of County Commissioners Cooperating. Larry Arrington, Dean 
proposal represents something they oppose. If they are powerless to change the real problem (e.g., unplanned development), residents may rally against one small outcome of the problem (e.g., logging this forest). If you can help identify the underlying issue or needs, you may be able to open up more alternatives for solutions. Do not be afraid to ask residents what they think; some resource professionals and extension agents have gone door-to-door to listen to community members.

Identify the common ground. Many groups in conflict mention that they are interested in working on the problem because they recognize a common goal— to make their community a better place, to improve the quality of life, or to protect a valuable resource. Keep this common goal at the fore as people begin to organize to work on the challenge. It may help folks remember what is really important.

Recognizing that they all want the same thing may allow the opposing parties to get to know each other, to listen to each others' concerns, and to begin to trust each others' intentions. They may even come up with a solution to the problem. If they generate the solution, it will be easier for them to bring goodwill and enthusiasm to its implementation than if the solution is imposed.

Keep lines of communication open. Meet with the community leaders regularly, if possible. When speaking with them, remember to acknowledge the values most people care about and connect your goals to their needs. Develop a collaborative approach to understanding the problem and developing solutions. Consider educational activities for each group (such as teaching deer hunters to diffuse tension when approaching animal-rights protesters) or use education to engage the community, perhaps by enlisting the help of a high school debate team or current issues course.

Develop good listening skills. Communication is a two-way street. Listening and understanding concerns will help you alter your message to be more readily heard. Good communication engages the audience, and a good communicator knows how to read and listen to the audience. Watch for nonverbal cues like wandering eyes, shuffling feet, and folded arms, and listen carefully to questions to make sure the concerns are being addressed.

Watch the audience. When giving a presentation, it helps to know as soon as possible that you have lost someone. Watch people's faces for agreement or questioning. Without putting anyone on the spot, you might ask a few individuals if they have some experience with what you are suggesting. Watch the body language, too. Crossed arms could be a sign that this person is feeling defensive. If the individual you call upon offers a different opinion, use his or her points to see how many of the group have had a similar experience. Ask if anyone has a solution to this problem. Never discount a comment or tell someone he or she is wrong. You may say, "Oh, I have not heard that before."

Use the right words. Sometimes experts use language differently than the general public. Each profession has specific words that carry special meanings, and it is easy to forget that everyone does not share your definitions of those words. Some people think of "plants" as shrubs or generic green things, rather than all photosynthetic organisms. To them, trees and flowers are not plants. Aim to choose words that your audience will relate to and understand.

Words also have value connotations. A suburban resident and a forester do not think about trees in the same way, and therefore may not communicate very well. Where a forester sees board feet or a reduced energy bill, a resident might see a personal friend, improved property value, or a celebratory event.

Be neutral. Groups of people will likely have a variety of perspectives on an interface issue. It is helpful to acknowledge these differences and if possible, respect their contributions. A nebulous, "That is an interesting idea" might enable you to let a dissenting voice speak without conveying agreement.

Conduct joint fact-finding missions. At the root of many conflicts is a problem with data. There may be two different versions of the facts. There may be uncertainty and missing data. Help the group identify what is known that they agree on, what is known that they disagree on, and what is unknown. Then jointly 
develop a procedure to find more data that can be trusted by all sides.

\section{Figure out where compromise can occur. A} real negotiation involves give and take on both sides. An extension agent may be in a position to assist various groups to recognize potential opportunities. Resource agencies may be limited by federal or state regulations, which can make negotiation difficult. If each party knows where it can bend and where it must be firm, individuals will be able to enter into agreements with more confidence.

Work carefully with the media. Develop a good relationship with reporters and editors and encourage them to present all perspectives of an issue (Figure 2). Some newspapers prefer to report on extreme views and forget the more reasoned compromise positions. Find out if the local newspaper has a citizen's advisory board or if the news editors meet regularly with residents looking for ideas and input on local issues. Try to establish yourself as a trusted source for environmentally related issues. This may help you convey facts and perspectives that may mitigate conflicts.

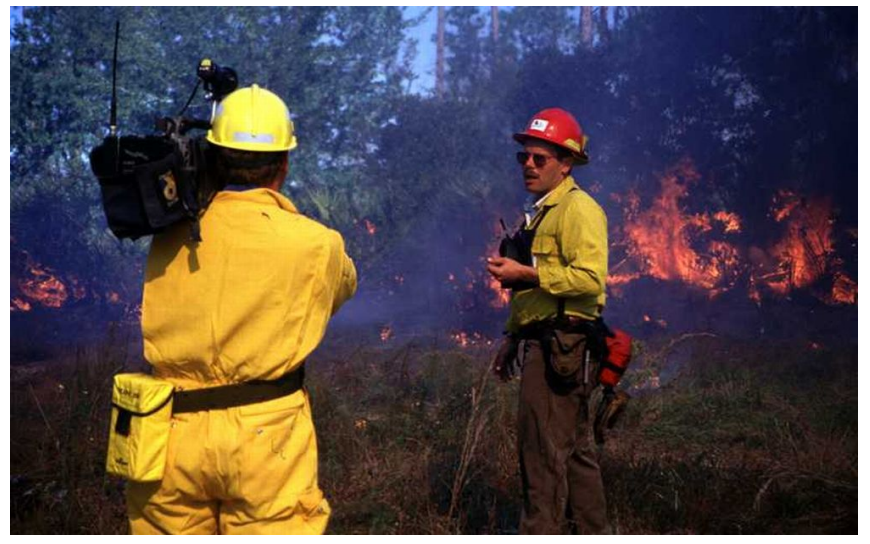

Figure 2. Inviting TV news reporters to a prescribed fire can allow a large audience to learn more about the value of this management tool. Credits: Larry Korhnak

Get help. In the midst of a conflict that involves your own agency or organization, it may be most prudent to obtain an outside negotiator or mediator to help manage the process of finding a solution. In contentious situations, the opposing forces may distrust each other so much that an outside opinion may be necessary for the parties to reach a decision. Getting help is not a sign of failure and may be the best move for developing a lasting solution.

\section{Summary}

The more extension agents and resource professionals know about their audiences and the context for the wildland-urban interface issues they face, the more likely they will be prepared with the appropriate language and communication strategies to explain the most relevant points, respect differences, and encourage fruitful compromise.

When interface conflicts already exist, carefully working with the stakeholders, seeking common ground, identifying places of agreement and disagreement, and creating a common vision for the community may help improve the situation. Conflicts are not easy to deal with, but a creative resolution has the potential to address a number of concerns with a positive outcome.

\section{Suggested Readings}

Wondolleck, J.M. and S.L. Yaffee. 2000. Making Collaboration Work: Lessons from Innovation in Natural Resource Management. Washington, DC: Island Press.

Fisher, R. and W. Ury. 1991. Getting to Yes: Negotiating Agreement Without Giving In. New York: Penguin Books. 